\title{
Weight changes in hypertensive patients with phlegm-dampness syndrome: an integrated proteomics and metabolomics approach
}

Chi Zhang ${ }^{1,2^{*+}} \oplus, \mathrm{Li} \mathrm{Li}^{3 \dagger}$, Shiping Cheng ${ }^{4+}$, Debajyoti Chowdhury ${ }^{5}$, Yong $\operatorname{Tan}^{3}$, Xinru Liu ${ }^{6}$, Ning Zhao ${ }^{3}$, Xiaojuan $\mathrm{He}^{3}$, Miao Jiang ${ }^{3}$, Cheng $\mathrm{Lu}^{3}$ and Aiping Lyu $\mathrm{u}^{5,7^{*}}$

\begin{abstract}
Background: Hypertension (HTN) patients who have phlegm-dampness syndrome (PDS) tend to be obese and have worse outcomes. However, the association of body weight (BW) changes and mechanisms underlying the pathophysiology of HTN-PDS are not well elucidated. This study aims to identify the longitudinal observations associated with the circulating markers discriminating BW changes of individuals with HTN-PDS.

Methods: An integrative approach relying on metabolomics and proteomics was applied to serum samples from HTN-PDS patients in a prospective cohort to identify the plausible mechanistic pathways underpinning HTN-PDS pathophysiology. Study participants were determined to have experienced a weight change if they showed a 5\%-15\% increase/reduction in BW at the end of the follow-up period. The joint pathway analysis and network analysis were performed using Ingenuity Pathway Analysis $\left(\mathrm{IPA}^{\circledR}\right)$ on the serum samples obtained from the participants over the period.

Results: The study involved 22 HTN-PDS patients who were overweight initially and were able to lose enough weight and 24 HTN-PDS individuals who developed overweight from normal BMI during a one-year follow-up. Our analysis suggested three types of phosphatidylcholine (PC) were altered. PC (22:2(13Z,16Z)/24:1(15Z)) and LysoPC (16:1(9Z)) were decreased in Queryweight gain samples, whereas the levels of PC (14:0/16:0) were increased in weight loss samples. The metabolomic analysis suggested 24 metabolites associated with HTN-PDS. Of them, 13 were upregulated and 11 were down-regulated. The two-dimensional difference gel electrophoresis (2D DIGE) identified 45 phosphorylated proteins got altered in the HTN-PDS patients, wherein 23 were up-regulated and 22 were downregulated. Integrated proteomic and metabolomics analyse acknowledged biomarkers PC, Complement C3, C4a/C4b, A2M and SERPINF1 as strong predictors for BW changes in HTN-PDS patients.
\end{abstract}

\footnotetext{
*Correspondence: saga618@126.com; aipinglu@hkbu.edu.hk

${ }^{\dagger}$ Chi Zhang, Li Li, Shiping Cheng are contributed equally to this work

${ }^{1}$ Dongzhimen Hospital, Beijing University of Chinese Medicine, Dongcheng District, Beijing 100700, China

${ }^{5}$ Institute of Integrated Bioinformedicine \& Translational Science, Hong

Kong Baptist University, Kowloon Tong, Hong Kong, China

Full list of author information is available at the end of the article
}

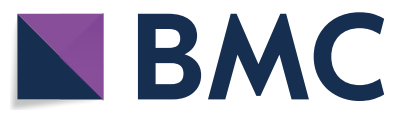

(c) The Author(s) 2021. This article is licensed under a Creative Commons Attribution 4.0 International License, which permits use, sharing, adaptation, distribution and reproduction in any medium or format, as long as you give appropriate credit to the original author(s) and the source, provide a link to the Creative Commons licence, and indicate if changes were made. The images or other third party material in this article are included in the article's Creative Commons licence, unless indicated otherwise in a credit line to the material. If material is not included in the article's Creative Commons licence and your intended use is not permitted by statutory regulation or exceeds the permitted use, you will need to obtain permission directly from the copyright holder. To view a copy of this licence, visit http://creativeco mmons.org/licenses/by/4.0/. The Creative Commons Public Domain Dedication waiver (http://creativecommons.org/publicdomain/ zero/1.0/) applies to the data made available in this article, unless otherwise stated in a credit line to the data. 
Conclusion: The combined serum proteomic and metabolomic profiling reveals a link between BW change and the complement system activity, altered phosphatidylcholine metabolism in HTN-PDS patients. Future studies with larger cohorts are required to strengthen and validate these findings.

Keywords: Hypertension, Chinese medicine syndrome, Metabolomics, Proteomics, Longitudinal study

\section{Background}

Hypertension (HTN) is one of the most important vascular risk factors worldwide $[1,2]$. The prevalence and incidence of HTN are increasing in all countries and contribute to the global burden of cardiovascular diseases [3]. Individuals with HTN are usually treated similarly, but prognoses differ and are often poorly understood [4]. In most cases amid clinical settings, those patients used to receive pharmacological treatments with certain types of antihypertensive drugs such as $\beta$-Blockers, ACE inhibitors, angiotensin receptor blockers, calcium channel blockers, thiazide and thiazide-type diuretics, aldosterone antagonists, direct renin inhibitors [4]. Overweight and obesity are well-established risk factors associated with the development of HTN $[5,6]$. They are also significantly associated with poor prognosis and increased complications $[7,8]$. Weight loss is recommended as an effective nonpharmacologic approach for lowering blood pressure (BP) [1]. Clinical guidelines provide recommendations for maintaining a normal BW for the management of HTN [3, 6]. Numerous epidemiologic studies and interventional trials have also demonstrated the major role of weight change in determining HTN risk [2, 9-12].

Chinese medicine (CM) categorizes HTN as internal disease symptoms. Syndrome differentiation (SD) is a comprehensive analysis of clinical information gained by the diagnostic CM procedures [13]. As previously reported, phlegm-dampness syndrome (PDS) is a common syndrome associated with HTN [14-16]. Phlegmdampness syndrome (PDS) is a syndrome that arises when dampness gathers to form phlegm, with different manifestations according to location: cough with profuse whitish expectoration and oppression in chest if phlegm obstructs the lung, and epigastric stuffiness, reduced food intake, and greasy taste in the mouth if phlegm accumulates in the spleen [17]. PDS individuals tend to be obese and have worse cardiac and vascular outcomes $[15,18,19]$. A mathematical model with more than 18,800 cases showed that compared with balanced constitution, the risk of obesity was also significantly higher with an OR of 4.34 and $95 \%$ CI of 3.52-5.36. Studies on the PDS are significantly important for the prediction and prevention of related diseases and maintenance of human health [14]. Transforming phlegm and eliminating dampness by weight management has been recommended $[19,20]$. However, few studies have compared the impact of weight changes in opposite directions in HTN patients with PDS, although this reversible factor provides an opportunity to control HTN and its vascular consequences.

During the development of HTN, tissues and organs undergo structural and functional changes those are characterized by specific alterations in the type and amount of various proteins expressed [21]. Few studies relying on proteomic approach have exposed a wide range of proteins expressed in serum samples [22, 23]. Hence, characterizing their expressions and differential fluctuations in parallel with the development and progressions of HTN must edify to distinguish some protruding pathophysiological pathways [22, 23]. As the protein levels influence the metabolic profile, in return, the concentrations of the metabolites may affect protein expressions [24]. The physiological activity of HTNPDS is complex, as using a single omics makes it hard to fully reveal the mechanism. Therefore, combining such wide information within the scope of systems biology approach deployed with human samples must enlighten more comprehensive understanding of the deep biology and pathophysiological processes of HTN $[25,26]$.

Here, in this longitudinal study, we have studied the metabolic changes in serum samples following exposure to $\mathrm{BW}$ changes throughout 1-year in individuals with HTN-PDS $(n=46$, weight gain $=24$, weight loss $=22)$ using an integrated proteomics and metabolomics analysis. The superiority of our approach is contented by its concurrent utilization of those omics techniques in determining the plausible biomarkers altered while $\mathrm{BW}$ changes and get reflected in the cohort of HTN patients longitudinally. It also ameliorated some of the deficiencies of each -omics technique when employed by itself. These markers may serve as potential therapeutic targets to manage HTN in clinical practice.

\section{Materials and methods Participants}

A total of 5638 individuals (1556 females, 27.6\%) undertook an annual health check-up at a community hospital in Beijing, China in 2016 and 2017. The inclusion criteria include the following: (1) participants were from a normal BMI to a high BMI $(\mathrm{N}-\mathrm{H})$ or from a high BMI to a normal $\mathrm{BMI}(\mathrm{H}-\mathrm{N})$ as determined by standardized measurements described below, (2) patients must have 
HTN, PDS [27] and be without any active cardiovascular diseases, (3) patients must be aged $\geq 18$ years at the beginning of the study, (4) participants were determined to have experienced BW changes if they showed a $5 \%-15 \%$ increase or reduction in their $\mathrm{BW}$ at the end of 12-month follow-up period [28], (5) an informant who knew the participant well must be available, and the patients were asked to have a repeat measurement of their weight within the follow-up tenure of one year. Exclusion criteria were a recent cardiovascular event, a weight gain/loss $>9 \mathrm{~kg}$ in the three months before the beginning of the study, the recent use of weight loss medications or medications that caused a weight gain, cancer cachexia that caused unintentional weight loss, or medical conditions that prevented the full participation in the research. Information was collected from a standardized clinical examination and questionnaires. BW was measured and the baseline questionnaires were completed for all the participants, followed by the questionnaires for their diet and lifestyle. All questionnaires were completed and returned at 12 months. Different therapeutic factors can largely affect the individual's metabolic profiles in the clinical study. To minimize those discrepancies, all the samples were collected in the morning after overnight fasting for all participants included in this study. Each participant's or patient's record was linked to their personal identification number, which is unique to every citizen in China, enabling the linkage of clinical data from the first and the second check-up for each individual. Consequently, 46 subjects comprised the cohort for this study (26 males and 20 females). Of them, 24 were $\mathrm{N}-\mathrm{H}$ subjects (12 males and 12 females) and 22 were $\mathrm{H}-\mathrm{N}$ subjects ( 14 males and 8 females).

\section{Standardized measurements}

During both the annual check-ups, the participants' height was measured to the nearest centimetre without shoes, and the BW was measured to the nearest half kilogram $(\mathrm{kg})$ wearing light clothes without shoes. Similar methods were applied in both the health check-ups. BMI was calculated by dividing a participant's BW in $\mathrm{kg}$ by the squared value of the body height in metres $(\mathrm{kg} /$ $\mathrm{m}^{2}$ ). The changes in the BMI between health check-ups were categorized into two types as $\mathrm{N}-\mathrm{H}$ and $\mathrm{H}-\mathrm{N}$. The $\mathrm{N}-\mathrm{H}$ BMI was considered $18.5 \leq \mathrm{BMI}<24 \mathrm{~kg} / \mathrm{m}^{2}$ initially and $\mathrm{BMI} \geq 24 \mathrm{~kg} / \mathrm{m}^{2}$ next year), and $\mathrm{H}-\mathrm{N}$ BMI was defined as the BMI at the first health check-up greater than or equal to $24 \mathrm{~kg} / \mathrm{m}^{2}$ and $18.5 \leq \mathrm{BMI}<24 \mathrm{~kg} / \mathrm{m}^{2}$ next year, according to the Chinese Obesity Working Group and World Health Organization categorization. At both health check-ups, each participant's blood pressure (BP) was measured by specially trained nurses or technicians with the participant sitting with their arm resting on a table at heart level. BP was measured using a Yuyue YE8700A (Yuyue, China). HTN was defined as systolic blood pressure (SBP) $\geq 140 \mathrm{mmHg}$ and/or diastolic blood pressure (DBP) $\geq 90 \mathrm{mmHg}[29,30]$. We calculated the change in the SBP and the DBP between health check-ups for each individual by subtracting the SBP and the DBP at the first health check-up from the SBP and the DBP at the second health check-up.

\section{Blood sampling}

Fasting blood samples were drawn from the participants via venipuncture by nurses. It was immediately centrifuged for $10 \mathrm{~min}$ at $3000 \mathrm{~g}$ at $4{ }^{\circ} \mathrm{C}$ to obtain the serum. $200 \mu \mathrm{l}$ of methanol was added to $100 \mu \mathrm{l}$ serum. The mixture was vortexed for $30 \mathrm{~s}$. Then the samples were centrifuged for $15 \mathrm{~min}$ at $4{ }^{\circ} \mathrm{C}$. Subsequently, the supernatant was collected and stored at $-80^{\circ} \mathrm{C}$.

\section{Metabolic profiling}

Liquid chromatography quadrupole-time-of-flight mass spectrometer (LC-Q-TOF-MS) analysis is based on our team's common metabolic profiling protocol [31]. An LCQ-TOF-MS analysis was performed with an Agilent 1200 Series LC Systems, Agilent technologies electrospray ionization and Agilent 6520 Accurate-Mass Q-TO. Separation of all of the samples was performed on Eclipse plus C18 $(3.6 \mathrm{~mm} \times 100 \mathrm{~mm}, 1.8 \mu \mathrm{m})$ with column temperature $45{ }^{\circ} \mathrm{C}$. Mass spectrometer detection was operated in the positive ion mode with the required settings [31]. All analyses were acquired by the instrument mass spray to improve reproducibility and accuracy. Leucine Enkephalin has been used as reference material for MS tuning and calibration at a concentration of $50 \mathrm{fmol} / \mu \mathrm{l}$. The data for each sample were normalized to a total area. Partial least squares discriminant analysis (PLS-DA) was performed for the metabolic profile analysis. The differentiation performance was validated by the area under the curve (AUC) of receiver operating characteristic curves. A multivariate analysis was done with the SIMCA-P software (Umetrics AB, Sweden) and SAS (v9.2, SAS Institute, Inc., Cary, NC.). A Chi-square test was performed for the analysis of the attribute data. The variance analysis was used for comparisons between the groups. A $p$-value of less than 0.05 was considered statistically significant.

Representative value (RV) is defined as the power of the metabolite to reflect the abnormality of the disease [31]. RV uses the fold change of the number of enzymes catalysing those metabolites and the importance of every enzyme to evaluate the indicative ability of the metabolite for the diseases. 


$$
\mathrm{RV}_{m}=\frac{F C_{m} \sum_{i=1}^{n_{e}} E P_{i}}{\sum_{j=1}^{n_{m}}\left(F C_{m_{j}} \sum_{i=1}^{n_{e}} E P_{i}\right)}
$$

$R V_{m}$ : the representative value for metabolite, $m$;

$E P_{i}$ : the network power of enzyme i that participates catalyzing metabolite, $\mathrm{m}$;

$\mathrm{n}_{\mathrm{e}}$ : the number of enzymes that participates in catalysing metabolite, $\mathrm{m}$;

$\mathrm{FC}_{\mathrm{m}}$ : the fold change value of metabolite, $\mathrm{m}$;

$\mathrm{n}_{\mathrm{m}}$ : the number of deregulated metabolites.

\section{Protein profiling}

The matched samples were crushed, dissolved in lysis buffer (7 M urea, $2 \mathrm{M}$ thiourea, 4\% CHAPS, 0.5\% IPG buffer, 3-10 NL, $0.5 \%$ Triton) containing protease inhibitor mixture. Protein identification and 2D gel separation were then carried out. The peptides were generated by trypsin. MS/MS spectra were processed by Analysis Software (v2.0, Applied Biosystems ${ }^{\mathrm{TM}}$ ) and searched using Mascot (v2.4, Matrix Science). The resulting MS/MS spectra were searched against the MS protein sequence database. Student's $t$ tests, two-sided were used to analyze differences in protein levels.

\section{Ingenuity pathway analysis (IPA)}

The analyses of canonical pathways, bio-functions and the networks were conducted by using the Ingenuity Pathway Analysis system (IPA, http://www.ingenuity. com) for the candidate metabolites and proteins to gain further insights into the typical metabolic alterations.

\section{Results}

\section{Baseline characteristics of participants}

A total of 46 patients were included. Their ages ranged from 41 to 76 years $(\mathrm{N}-\mathrm{H} 62.8 \pm 8.3 \mathrm{vs}$. $\mathrm{H}-\mathrm{N} 64.2 \pm 11.9)$. Cases in men were in the majority (56.5\%). After oneyear follow up, BMI change from $24.3 \pm 0.5$ to $25.7 \pm 0.7$ in $\mathrm{N}-\mathrm{H}$ group and $26.1 \pm 1.4$ to $23.8 \pm 0.9$ in $\mathrm{H}-\mathrm{N}$ group, respectively. No clinically relevant differences were observed between two groups by different factors such as exercises, eating habits, dairy foods, fruits, vegetables, beverage, meat, sweets, alcohol, smoking influencing both the BW and metabolic changes potentially. The demographic and baseline clinical characteristics of the enrolled participants are shown in Table 1.

\section{Identification of metabolites and proteins}

Ten metabolites were identified in the $\mathrm{N}-\mathrm{H}$ HTNPDS subjects, and 14 metabolites were identified in the H-N HTN-PDS subjects (Table 2). The cut-off for the fold change of each metabolite and the ratio of each protein in the HTN-PDS patients to those in the control group was set to greater than 1.01-fold, and the
Table 1 Baseline characteristics and clinical measurements of 46 participants during the follow-up

\begin{tabular}{|c|c|c|}
\hline \multirow[t]{2}{*}{ Variables } & \multicolumn{2}{|c|}{ BMI change categorization } \\
\hline & $\mathrm{N}-\mathrm{H}(\mathrm{n}=24)$ & $\mathrm{H}-\mathrm{N}(\mathrm{n}=22)$ \\
\hline Age (y) & $62.8 \pm 8.3$ & $64.2 \pm 11.9$ \\
\hline Men (\%) & $12(50.0 \%)$ & $14(63.7 \%)$ \\
\hline \multicolumn{3}{|l|}{ Race or ethnic group } \\
\hline Han & 24 & 22 \\
\hline Others & 0 & 0 \\
\hline $\mathrm{BMI} O(\mathrm{~kg} / \mathrm{m} 2)$ & $24.3 \pm 0.5$ & $26.1 \pm 1.4$ \\
\hline BMI 1 (kg/m2) & $25.7 \pm 0.7$ & $23.8 \pm 0.9$ \\
\hline Waist 0 (cm) & $85.50 \pm 5.16$ & $89.48 \pm 6.96$ \\
\hline Waist 1 (cm) & $86.75 \pm 6.09$ & $87.91 \pm 6.87$ \\
\hline Glucose 0 (mmol/L) & $5.77 \pm 0.47$ & $5.87 \pm 0.50$ \\
\hline Glucose 1 (mmol/L) & $5.65 \pm 0.41$ & $5.69 \pm 0.34$ \\
\hline Systolic blood pressure $0(\mathrm{~mm} \mathrm{Hg})$ & $146.38 \pm 16.24$ & $147.10 \pm 16.45$ \\
\hline Systolic blood pressure 1 (mm Hg) & $148.59 \pm 16.02$ & $146.05 \pm 17.64$ \\
\hline Diastolic blood pressure $0(\mathrm{~mm} \mathrm{Hg})$ & $85.50 \pm 5.16$ & $89.48 \pm 6.96$ \\
\hline Diastolic blood pressure $1(\mathrm{~mm} \mathrm{Hg})$ & $86.55 \pm 5.90$ & $87.71 \pm 8.36$ \\
\hline Total cholesterol 0 (mmol/L) & $5.48 \pm 1.11$ & $5.26 \pm 1.49$ \\
\hline Total cholesterol 1 (mmol/L) & $5.33 \pm 0.83$ & $4.77 \pm 0.94$ \\
\hline Triglyceride 0 (mmol/L) & $1.65 \pm 0.82$ & $1.95 \pm 1.32$ \\
\hline Triglyceride 1 (mmol/L) & $1.66 \pm 0.76$ & $1.70 \pm 1.26$ \\
\hline $\begin{array}{l}\text { Tobacco consumption Packs per year, } \\
\text { mean } \pm S D\end{array}$ & $34.61 \pm 19.33$ & $29.87 \pm 19.54$ \\
\hline \multicolumn{3}{|l|}{ Regular cigarette smoking } \\
\hline Yes & 7 & 5 \\
\hline No & 17 & 16 \\
\hline Unknown & 0 & 1 \\
\hline \multicolumn{3}{|l|}{ Regular alcohol consumption } \\
\hline Yes & 5 & 3 \\
\hline No & 18 & 19 \\
\hline Unknown & 1 & 0 \\
\hline \multicolumn{3}{|l|}{ Regular physical activity } \\
\hline Yes & 9 & 11 \\
\hline No & 15 & 11 \\
\hline Unknown & 0 & 0 \\
\hline \multicolumn{3}{|l|}{ Sodium intake } \\
\hline$\leq 6 \mathrm{~g} /$ day & 5 & 6 \\
\hline$>6 \mathrm{~g} /$ day & 15 & 14 \\
\hline Unknown & 4 & 2 \\
\hline \multicolumn{3}{|l|}{ Food groups (no. of servings/day) } \\
\hline Fruits and juices & 1.2 & 1.3 \\
\hline Vegetables & 1.1 & 1.4 \\
\hline Grains & 1.8 & 1.6 \\
\hline Regular-fat dairy & 2.1 & 2.6 \\
\hline Nuts, seeds, and legumes & 1.8 & 1.9 \\
\hline Beef, pork & 1.2 & 1.1 \\
\hline Poultry & 0.9 & 1.0 \\
\hline Fish & 0.3 & 0.5 \\
\hline Snacks and sweets & 1.1 & 0.9 \\
\hline
\end{tabular}


Table 1 (continued)

\section{Data are mean S.E}

1 pack per year is equal to smoking 1 pack per year

$B M I$ body mass index, 0 baseline, 1 after 1 year follow up

FDR $\mathrm{p}$-value as $\mathrm{p}<0.01$. Three types of PCs were found to get altered. PC $(22: 2(13 Z, 16 Z) / 24: 1(15 Z))$, LysoPC $(16: 1(9 Z))$ were decreased in $\mathrm{N}-\mathrm{H}$ samples, whereas the levels of PC (14:0/16:0) were increased in $\mathrm{H}-\mathrm{N}$ samples. The results also indicated the levels of phosphatidylinositol, PI(16:0/20:4(5Z,8Z,11Z,14Z)), all-trans-Decaprenyl diphosphate were significantly increased in the weight gain samples. Besides, the levels of 5-amino-1-(5phospho-D-ribosyl) imidazole-4-carboxylate,3b,5a,6bCholestanetriol, 2-aminomuconic acid semialdehyde were significantly decreased in the BW loss samples. A phospho-antibody microarray was used to make a list of proteins whose phosphorylation states were increased or decreased in the HTN-PDS patients, and 45 phosphorylated proteins in the HTN-PDS patients were found to be altered, with 23 up-regulated and 22 down-regulated (Table 3).

\section{Biological pathway analysis}

Biological association network and pathways related to a series of identified metabolites were identified using IPA software. Using this we were able to reconstruct the metabolite networks and proteins networks for $\mathrm{H}-\mathrm{N} / \mathrm{N}-\mathrm{H}$ groups of participants. Those reconstructed networks were generated using the fusion of proteomics and metabolomics data. They helped to identify a series of metabolites and proteins associated with several key biological processes and signalling pathways. Firstly, focusing with the reconstructed metabolites networks, 28 prominent nodes were identified related to the biological functions including but not limited to choline biosynthesis, sphingomyelin

Table 2 Metabolites detected by LC-Q-TOF-MS in the validation sample set (HTN-PDS patients with body mass index from normal to high $(\mathrm{N}-\mathrm{H})$ )/high to normal $(\mathrm{H}-\mathrm{N}))$ and their biological variation

\begin{tabular}{|c|c|c|c|c|c|}
\hline Rt & Mass & Name & Formula & Folder & RV \\
\hline \multicolumn{6}{|c|}{ Hypertensive patients with BMI from normal to high $(\mathrm{N}-\mathrm{H})$} \\
\hline 883.853 & 923.7343 & $P C(22: 2(13 Z, 16 Z) / 24: 1(15 Z))$ & $\mathrm{C} 54 \mathrm{H} 102 \mathrm{NO} 8 \mathrm{P}$ & -4.2589 & 0.30 \\
\hline 488.784 & 493.3168 & LysoPC(16:1(9Z)) & $\mathrm{C} 24 \mathrm{H} 48 \mathrm{NO} 7 \mathrm{P}$ & -1.3129 & 0.20 \\
\hline 502.977 & 520.2719 & Dolichyl diphosphate & $\mathrm{C} 25 \mathrm{H} 46 \mathrm{OPP} 2$ & 1.1990 & 0.10 \\
\hline 515.839 & 761.4996 & PE(16:1 (9Z)/22:6(4Z,7Z,10Z,13Z,16Z,19Z)) & $\mathrm{C} 43 \mathrm{H} 72 \mathrm{NO} 8 \mathrm{P}$ & 1.7277 & 0.10 \\
\hline 275.788 & 491.0008 & dATP & $\mathrm{C} 10 \mathrm{H} 16 \mathrm{~N} 5 \mathrm{O} 12 \mathrm{P} 3$ & -1.3376 & 0.08 \\
\hline 863.462 & 858.5258 & $\mathrm{PI}(16: 0 / 20: 4(5 Z, 8 Z, 11 Z, 14 Z))$ & $\mathrm{C} 45 \mathrm{H} 79013 \mathrm{P}$ & 5.7789 & 0.06 \\
\hline 868.575 & 858.5692 & All-trans-Decaprenyl diphosphate & $\mathrm{C} 50 \mathrm{H} 84 \mathrm{O} 7 \mathrm{P} 2$ & 5.7789 & 0.02 \\
\hline 256.068 & 432.066 & Se-Adenosylselenohomocysteine & $\mathrm{C} 14 \mathrm{H} 20 \mathrm{~N} 6 \mathrm{O} 5 \mathrm{Se}$ & 1.0574 & 0.02 \\
\hline 1170.565 & 412.0185 & $d I D P$ & $\mathrm{C} 10 \mathrm{H} 14 \mathrm{~N} 4 \mathrm{O} 10 \mathrm{P} 2$ & -2.4528 & 0.01 \\
\hline 277.447 & 482.9845 & Cytidine triphosphate (CTP) & $\mathrm{C} 9 \mathrm{H} 16 \mathrm{~N} 3 \mathrm{O} 14 \mathrm{P3}$ & 1.2429 & 0.01 \\
\hline \multicolumn{6}{|c|}{ Hypertensive patients with BMI from high to normal $(\mathrm{H}-\mathrm{N})$} \\
\hline 1141.523 & 705.5309 & $P C(14: 0 / 16: 0)$ & $\mathrm{C} 38 \mathrm{H} 76 \mathrm{NO} 0 \mathrm{P}$ & 6.4684 & 0.32 \\
\hline 652.833 & 420.3603 & 3b,5a,6b-Cholestanetriol & $\mathrm{C} 27 \mathrm{H} 48 \mathrm{O} 3$ & -7.4571 & 0.16 \\
\hline 521.412 & 722.444 & Octaprenyl diphosphate & $\mathrm{C} 40 \mathrm{H} 68 \mathrm{O} 7 \mathrm{P} 2$ & 2.4689 & 0.12 \\
\hline 190.274 & 141.0426 & 2-aminomuconic acid semialdehyde & $\mathrm{C} 6 \mathrm{H} 7 \mathrm{NO} 3$ & -4.6339 & 0.10 \\
\hline 61.626 & 129.0426 & Pyroglutamic acid & $\mathrm{C} 5 \mathrm{H} 7 \mathrm{NO} 3$ & 6.5815 & 0.08 \\
\hline 223.019 & 189.0637 & N-Acetyl-L-glutamic acid & $\mathrm{C} 7 \mathrm{H} 11 \mathrm{NO} 5$ & 3.2199 & 0.06 \\
\hline 324.918 & 462.2618 & Retinyl beta-glucuronide & $\mathrm{C} 26 \mathrm{H} 38 \mathrm{O} 7$ & 4.5571 & 0.05 \\
\hline 89.597 & 168.0283 & Uric acid & $\mathrm{C} 5 \mathrm{H} 4 \mathrm{~N} 4 \mathrm{O} 3$ & -1.7995 & 0.03 \\
\hline 864.632 & 130.063 & 3-Methyl-2-oxovaleric acid & $\mathrm{C} 6 \mathrm{H} 10 \mathrm{O} 3$ & 3.3563 & 0.02 \\
\hline 190.188 & 175.0633 & 3-Indoleacetic Acid & $\mathrm{C} 10 \mathrm{H} 9 \mathrm{NO} 2$ & -1.0880 & 0.02 \\
\hline 66.389 & 190.0114 & Oxalosuccinic acid & $\mathrm{C} 6 \mathrm{H} 6 \mathrm{O} 7$ & -3.0817 & 0.02 \\
\hline 51.332 & 339.0468 & $\begin{array}{l}\text { 5-amino-1-(5-phospho-D-ribosyl)imidazole- } \\
\text { 4-carboxylate }\end{array}$ & $\mathrm{C9H14N3O9P}$ & -13.5318 & 0.01 \\
\hline 63.879 & 112.016 & 2-Furoic acid & $\mathrm{C} 5 \mathrm{H} 4 \mathrm{O} 3$ & -2.4225 & 0.01 \\
\hline 625.18 & 362.2093 & 18-Hydroxycorticosterone & $\mathrm{C} 21 \mathrm{H} 30 \mathrm{O} 5$ & 3.9819 & 0.01 \\
\hline
\end{tabular}

"Folder" refers to the "normal BMI vs. high BMI" change value; RV is the power of the metabolite to reflect the abnormal state in the disease LysoPC: Lysophosphatidylcholine; PC: Phosphatidylcholine 
Table 3 Identified proteins in HTN-PDS patients with body mass index (BMI) from normal to high (N-H)

\begin{tabular}{|c|c|c|c|c|c|}
\hline ANOVA (p) & Folder & Protein ID & Gene name & Score & $\begin{array}{l}\text { No. of peptide } \\
\text { identified }\end{array}$ \\
\hline \multicolumn{6}{|c|}{ Hypertensive patients with BMI from normal to high $(\mathrm{N}-\mathrm{H})$} \\
\hline 0.011 & +2.3 & Apolipoprotein A-I & APOA 1 & 105.00 & 2 \\
\hline 0.010 & +2.2 & Angiotensinogen & AGT & 316.00 & 3 \\
\hline 0.013 & +2.1 & Apolipoprotein D & APOD & 41.00 & 2 \\
\hline 0.019 & +2.1 & Serum amyloid P-component & APCS & 176.00 & 3 \\
\hline 0.014 & +1.6 & Apolipoprotein E & APOE & 300.00 & 7 \\
\hline 0.028 & -1.5 & Haptoglobin-related protein & HPR & 42.00 & 3 \\
\hline 0.033 & -1.5 & Alpha-2-macroglobulin & $\mathrm{A} 2 \mathrm{M}$ & 216.00 & 4 \\
\hline 0.035 & -1.5 & Mannan-binding lectin serine protease 2 & MASP2 & 36.00 & 1 \\
\hline 0.007 & -1.6 & Antithrombin-III & SERPINC1 & 92.00 & 3 \\
\hline 0.042 & -1.6 & Keratin, type I cytoskeletal 14 & KRT14 & 51.00 & 2 \\
\hline 0.004 & -1.7 & Complement factor I & $\mathrm{CFI}$ & 116.00 & 5 \\
\hline 0.044 & -1.7 & Complement factor H-related protein 1 & CFHR1 & 117.00 & 3 \\
\hline $6.14 \mathrm{E}-05$ & -1.8 & Plasma serine protease inhibitor & SERPINA5 & 141.00 & 3 \\
\hline 0.003 & -1.8 & Pigment epithelium-derived factor & SERPINF1 & 907.00 & 9 \\
\hline 0.034 & -1.8 & ELAV-like protein 3 & ELAVL3 & 37.00 & 1 \\
\hline 0.038 & -1.8 & Apolipoprotein L1 & APOL1 & 221.00 & 4 \\
\hline 0.047 & -1.8 & Keratin, type I cytoskeletal 10 & KRT10 & 208.00 & 4 \\
\hline 0.037 & -2.0 & Mitochondrial coenzyme A transporter & SLC25A42 & 35.00 & 1 \\
\hline 0.039 & -2.0 & Haptoglobin & HP & 118.00 & 3 \\
\hline 0.042 & -2.0 & Apolipoprotein C-III & APOC3 & 42.00 & 1 \\
\hline 0.022 & -2.5 & Hepatocyte growth factor-like protein & MST1 & 99.00 & 4 \\
\hline 0.014 & -2.7 & Complement C3 & C3 & 126.00 & 3 \\
\hline 0.004 & -6.5 & Complement C4-A & C4A & 106.00 & 4 \\
\hline \multicolumn{6}{|c|}{ Hypertensive patients with BMI from high to normal $(\mathrm{H}-\mathrm{N})$} \\
\hline $1.02 \mathrm{E}-05$ & +8.8 & Prothrombin & $\mathrm{F} 2$ & 206.00 & 2 \\
\hline 0.030 & +3.8 & Serum amyloid A-4 protein & SAA4 & 428.00 & 3 \\
\hline $1.41 \mathrm{E}-04$ & +3.2 & Hemopexin & HPX & 123.00 & 3 \\
\hline 0.014 & +2.9 & Complement factor H-related protein 1 & CFHR1 & 722.00 & 4 \\
\hline 0.013 & +2.5 & Complement component C6 & C6 & 480.00 & 3 \\
\hline 0.001 & +2.5 & Complement C3 & C3 & 290.00 & 5 \\
\hline 0.023 & +2.4 & Fibrinogen alpha chain & FGA & 58.00 & 1 \\
\hline 0.038 & +2.0 & Beta-2-glycoprotein 1 & $\mathrm{APOH}$ & 152.00 & 3 \\
\hline 0.006 & +1.8 & Apolipoprotein E & APOE & 134.00 & 2 \\
\hline 0.019 & +1.7 & Insulin-like growth factor II & IGF2 & 94.00 & 2 \\
\hline 0.011 & +1.7 & Keratin, type II cytoskeletal 1 & KRT1 & 315.00 & 7 \\
\hline 0.005 & +1.7 & Pigment epithelium-derived factor & SERPINF1 & 192.00 & 5 \\
\hline 0.011 & +1.6 & Alpha-2-macroglobulin & $\mathrm{A} 2 \mathrm{M}$ & 318.00 & 4 \\
\hline 0.010 & +1.6 & Plasminogen & PLG & 58.00 & 2 \\
\hline 0.011 & +1.5 & Complement C4-A & C4A & 745.00 & 3 \\
\hline 0.010 & +1.5 & Inter-alpha-trypsin inhibitor heavy chain $\mathrm{H} 1$ & $\mathrm{ITIH} 1$ & 188.00 & 1 \\
\hline 0.003 & +1.5 & Apolipoprotein A-IV & APOA4 & 198.00 & 6 \\
\hline $1.84 \mathrm{E}-04$ & +1.5 & Keratin, type I cytoskeletal 10 & KRT10 & 1037.00 & 13 \\
\hline 0.019 & -1.5 & Complement factor I & $\mathrm{CFI}$ & 69.00 & 1 \\
\hline 0.045 & -1.6 & N-acetylmuramoyl-L-alanine amidase & PGLYRP2 & 142.00 & 3 \\
\hline 0.014 & -1.7 & Apolipoprotein L1 & APOL1 & 365.00 & 6 \\
\hline 0.038 & -1.8 & Apolipoprotein C-III & APOC3 & 126.00 & 1 \\
\hline
\end{tabular}

"Folder" refers to the "high BMI vs. normal BMI" change value 
metabolism. Our analysis returned with some knowledge on metabolites (such as indoleacetic acid, uric acid, carboxyaminoimidazole in $\mathrm{H}-\mathrm{N}$ network, and phosphatidylcholine, phosphatidylinositol, CTP in $\mathrm{N}-\mathrm{H}$ network), proteins (such as APOL1, APOC3 in $\mathrm{H}-\mathrm{N}$ networks, and APOD, APOA1 in $\mathrm{N}-\mathrm{H}$ network) and their associations with the pathways like choline biosynthesis, mTOR signalling, sphingomyelin metabolism. Their dependencies to each other have been depicted in Fig. 1A. This also indicated a wide range of metabolites those were up-regulated and down-regulated. For example, the metabolites such as phosphatidylcholine, 18-hydroxycorticosterone, pyrrolidonecarboxylic acid were found to be upregulated in $\mathrm{H}-\mathrm{N}$ cohort and phosphatidylinositol, trans-decaprenyl diphosphate in $\mathrm{N}-\mathrm{H}$ cohort. On the other side, the metabolites such as indoleacetic acid, uric acid, carboxyaminoimidazole were found to be down-regulated in $\mathrm{H}-\mathrm{N}$ cohort and phosphatidylcholine, acyl-glycerophosphocholine in $\mathrm{N}-\mathrm{H}$ cohort (Fig. 1A). The physical connections, as well as the functional implications among them, were established. Next, we were able to identify six important biological pathways out of those changes in the level of the metabolites. They were choline biosynthesis III, RhoA signalling, sphingomyelin metabolism, mTOR signalling, p70S6k signalling and phospholipases $\mathrm{C}$ signalling (Fig. 1B). Among them, the Phosphatidylcholine (PC) signalling pathway was determined to be the most significant (Fig. 1C). Secondly, the $\mathrm{H}-\mathrm{N} / \mathrm{N}-\mathrm{H}$ proteins network analysis, 45 prominent nodes were identified related to the biological functions such as LXR/RXR activation, FXR/RXR activation, complement system activation. Our analysis returned with some knowledge on metabolites, proteins (as described above) and their associations with the pathways like LXR/RXR and FXR/RXR activation, acute phase response signalling, complement system activation. Their dependencies to each other have been depicted in Fig. 3A. This finding indicated a wide range of proteins beings up-regulated and down-regulated. For example, C3, F2, SERPINF1 were found to be up-regulated in $\mathrm{H}-\mathrm{N}$ network, and APOD, APOE, APOA1 in $\mathrm{N}-\mathrm{H}$ networks. And APOC3, APOL1, CF1 were found to be down-regulated in $\mathrm{H}-\mathrm{N}$ network, wherein MST1, APOL1, SERPINC1 got down-regulated in $\mathrm{N}-\mathrm{H}$ network (Fig. 2A). Then, we investigated the LXR/RXR activation, FXR/RXR activation, acute phase response signalling and complement system successively. It indicated several important proteins associated with the biological functions of those pathways (Fig. 2B). Of them, Complement C3, Complement C4a/C4b, Alpha-2-macroglobulin (A2M), Serpin family $\mathrm{F}$ member 1 (SERPINF1) were found to be most significant (Fig. 2C).

\section{A fusion of insights obtained from metabolomics and proteomics study}

To interpret the data obtained from metabolomics and proteomics study, we constructed a correlation network that embodied the interconnections between the variations among proteins and metabolites. We performed the analysis of the networks comprising of Complement C3, Complement C4a/C4b, A2M, SERPINF1, and PC. Interaction between $\mathrm{C} 3$ and $\mathrm{C} 4 \mathrm{~A} / \mathrm{C} 4 \mathrm{~B}$ were found to be direct, wherein the interaction between LPA and phosphatidylcholine were identified as indirect. All detailed direct and indirect interactions along with their functional classes have been depicted in Fig. 3. Our results revealed that the primary disturbed pathways in response to Phosphatidylcholine metabolism were choline biosynthesis III, RhoA signalling, sphingomyelin metabolism, mTOR signalling, p70S6k signalling and phospholipases $\mathrm{C}$ signalling. Besides, we also identified the most relevant pathway of the complement system includes LXR/RXR activation, FXR/RXR activation, and acute phase response signalling. This interaction network offered a global view of potentially functional relationships between metabolites, connected proteins, and pathways.

\footnotetext{
(See figure on next page.)

Fig. 1 Biological network and canonical pathways related to the identified metabolites in Hypertensive Patients with Phlegm-Dampness Syndrome. A Ingenuity Pathway Analysis (IPA)-identified H-N/N-H metabolites network. The N-H BMI was considered $18.5 \leq \mathrm{BMI}<24 \mathrm{~kg} / \mathrm{m}^{2}$ initially and $\mathrm{BMI} \geq 24 \mathrm{~kg} / \mathrm{m}^{2}$ next year), and $\mathrm{H}-\mathrm{N}$ BMI was defined as the BMl at the first health check-up greater than or equal to $24 \mathrm{~kg} / \mathrm{m}^{2}$ and $18.5 \leq \mathrm{BMl}<24 \mathrm{~kg} / \mathrm{m}^{2}$ next year, according to the Chinese Obesity Working Group and World Health Organization categorization. Molecules in the network are represented as nodes, and the biological relationship between two nodes is represented as a line. The coloured symbols represent the metabolites, proteins and pathways that occurred in the findings, while the transparent entries are molecules from the Ingenuity Knowledge Database. Red symbols represent up-regulated metabolites or proteins, the light red symbols represent the modestly up-regulated metabolites/ proteins, green symbols represent down-regulated metabolites/proteins, and the light green symbols represent the modestly down-regulated metabolites/proteins. Solid lines between molecules indicate a direct physical relationship between the molecules, while dotted lines indicate indirect functional relationships. B IPA identified six biological pathways. The Y-axis represents the top functions as calculated by IPA based on differentially expressed genes, and the $X$-axis represents the ratio of a number of genes from the dataset that map to the pathway and the number of all known genes ascribed to the pathway. The orange threshold line marks the $p=0.05$. The threshold of $p$-value $<0.05$ as calculated by Fischer's test. C IPA identified most highly rated network. The network representation of the most highly rated network. Phosphatidylcholine (PC) shaded dark blue are upregulated and those that are light blue are downregulated. A solid line represents a direct interaction between the two metabolites
} 


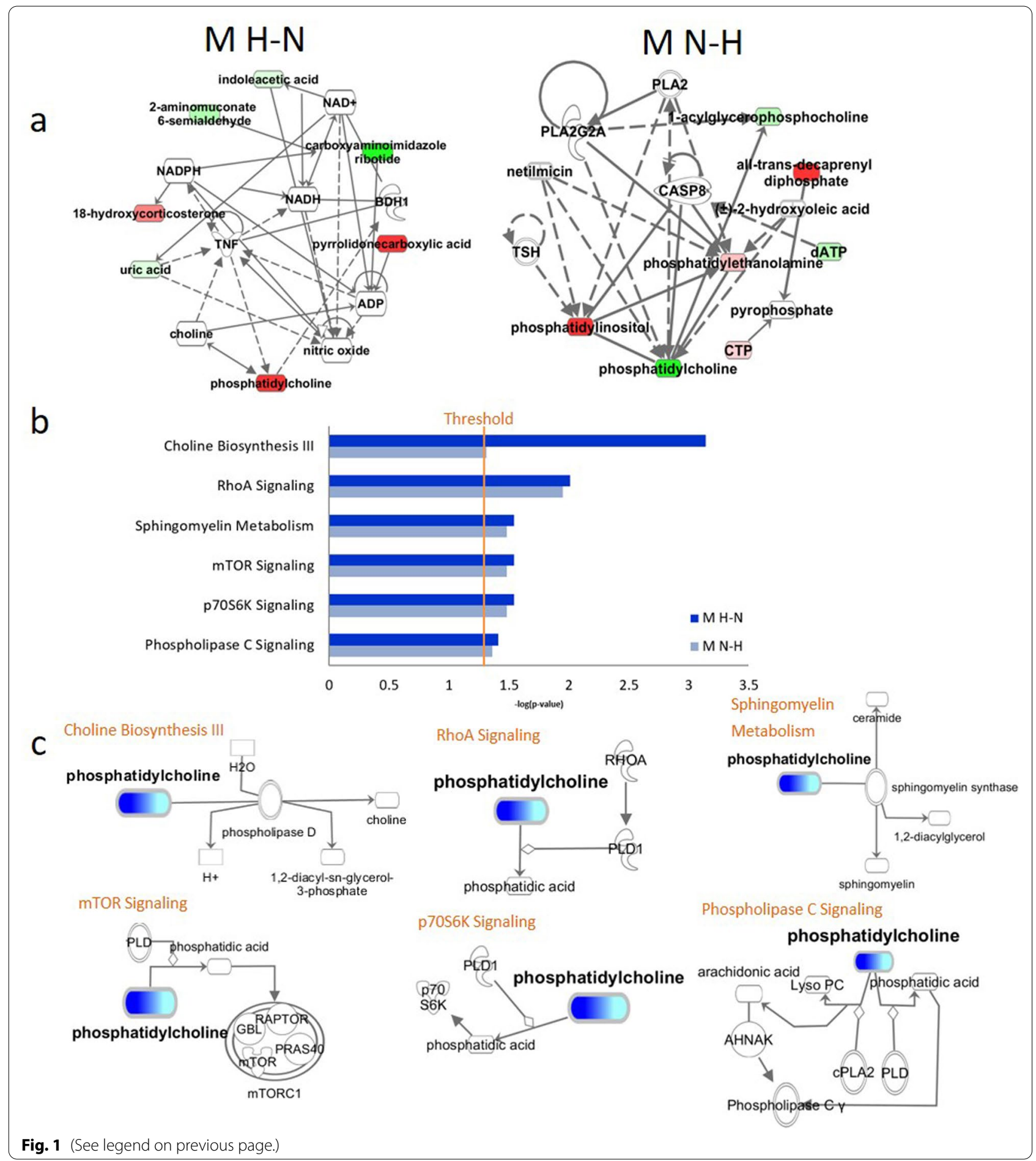

\section{Discussions}

Using proteomics and metabolomics together, our study strongly endorses the strongest predictors and the associated signalling pathways that are functionally related to longitudinal weight changes of HTN-PDS. It also claims a prominent correlation between body weight and HTN-PDS. Our approach is a pioneer in its class using such approaches together to establish PC, Complement C3, C4a/C4b, A2M and SERPINF1 as markers for HTN control from a longitudinal study. Metabolomic data and 
proteomic data, those two major directions will be further discussed in detail.

\section{Phosphatidylcholines as signature metabolic markers for HTN-PDS patients}

The metabolomic study has identified various types of PCs getting altered in HTN-PDS patients. Interestingly, three candidates, $\mathrm{PC}(22: 2(13 \mathrm{Z}, 16 \mathrm{Z}) / 24: 1(15 \mathrm{Z}))$, LysoPC(16:1(9Z)) and $P C(14: 0 / 16: 0)$ were characterized to exert the strongest impact in discriminating $\mathrm{H}-\mathrm{N} / \mathrm{N}-$ $\mathrm{H}$ subjects (Fig. 2C). PCs are a type of glycerophospholipid containing the polar phosphocholine at the head and two nonpolar fatty acid hydrocarbon chains as tails. They are the major membrane-forming phospholipid in mammalian cells $[32,33]$. With the accumulation of fat molecules, the concentration of PCs used to get altered. Significantly higher abundance of the PCs was found in overweight compared to normal subjects $(\mathrm{N}-\mathrm{H}$ : - 4.2589; $\mathrm{H}-\mathrm{N}$ : 6.4684). This signifies PCs as potential indicators for differential states of metabolic activity between normal and overweight HTN-PDS patients.

Although HTN is closely linked to dyslipidaemia [34], there are quite a limited number of cohorts exists that investigated blood parameters in PC metabolism concerning HTN [35]. A study with the US-Hispanic population elucidated the associations of PCs with HTN using serum-derived lipidomic profiling [36]. Moreover, knowledge suggests that the most PCs are formed by the choline pathway, and in our study, we have attempted to understand the underlying relationships of the lipid, blood pressure nexus with weight change with longitudinal evidence. Our results showed a coherent consistency with the existing benchmark studies while establishing the functional associations with the identified biological pathways and interpreting their terms. Previous studies indicated the elevated levels of sphingomyelin and PC are significantly interrelated in patients with HTN [37]. Sphingomyelin metabolism plays critically in communicating between cells and their environments, being involved in signal transduction and metabolite exchange [38]. Our results indicated that the mechanisms controlling HTN by weight change are more likely to be linked with enhanced metabolic efficiency. Obesity affects mTOR/p70S6k pathway (Figs. 1C, 3). A report demonstrated that weight loss critically regulates the mTOR/p70S6k pathway by promoting protein synthesis in rat models with obesity [39]. Several studies have examined the role of Rho-kinase (ROCK) signalling in cardiac remodelling associated with obesity [40]. ROCK is a downstream effector molecule of a key signalling factor, Ras homolog gene family member A (RhoA). RhoA is a small GTPase that used to get involved in diverse cellular functions. RhoA signalling through its downstream effector, ROCK has been implicated in the pathogenesis of cardiac fibrosis. RhoA activation has significant effects on various cardiovascular diseases, mainly HTN $[41,42]$. In this direction, metabolite profiling helped in identifying some lipid metabolites such as PI (16:0/20:4(5Z, 8Z, 11Z, 14Z)), Pyroglutamic acid and 3b,5a,6b-Cholestanetriol as differentially abundant in the serum of $\mathrm{N}-\mathrm{H} / \mathrm{H}-$ $\mathrm{N}$ groups, respectively. A research study detected serum adiponectin (APN) levels in 250 hypertensive patients (137 with PDS and 113 non PDS) by showed significant differences in serum APN levels between PDS and nonPDS patients $(5.07 \pm 0.35 \mu \mathrm{g} / \mathrm{mL}$ vs. $6.41 \pm 0.39 \mu \mathrm{g} / \mathrm{mL}$, $\mathrm{p}=0.045)$ [43]. Moreover, in CM theory, the same strategy is used to treat patients with multiple diseases who have the same syndrome. Multiple diseases with PDS tend to be obese and have worse clinical outcomes [14]. Our results can be used to optimize personalized treatment for high-risk patients, or be used as key metabolites to follow when regulating body weight.

\section{Complement system activity}

Our proteome analysis revealed a higher abundance of lipoprotein and Complement components. Among

\footnotetext{
(See figure on next page.)

Fig. 2 Biological network and canonical pathways related to the identified proteins in Hypertensive Patients with Phlegm-Dampness Syndrome. A Ingenuity Pathway Analysis (IPA)-identified H-N/N-H proteins network. The N-H BMI was considered $18.5 \leq \mathrm{BMl}<24 \mathrm{~kg} / \mathrm{m}^{2}$ initially and $\mathrm{BMI} \geq 24 \mathrm{~kg} / \mathrm{m}^{2}$ next year), and $\mathrm{H}-\mathrm{N}$ BMI was defined as the BMl at the first health check-up greater than or equal to $24 \mathrm{~kg} / \mathrm{m}^{2}$ and $18.5 \leq \mathrm{BMl}<24 \mathrm{~kg} / \mathrm{m}^{2}$ next year, according to the Chinese Obesity Working Group and World Health Organization categorization. Molecules in the network are represented as nodes, and the biological relationship between two nodes is represented as a line. The coloured symbols represent the metabolites, proteins and pathways that occurred in the findings, while the transparent entries are molecules from the Ingenuity Knowledge Database. Red symbols represent up-regulated metabolites or proteins, the light red symbols represent the modestly up-regulated metabolites/ proteins, green symbols represent down-regulated metabolites/proteins, and the light green symbols represent the modestly down-regulated metabolites/proteins. Solid lines between molecules indicate a direct physical relationship between the molecules, while dotted lines indicate indirect functional relationships. B IPA identified pathway: LXR/RXR activation, FXR/RXR activation, acute phase response signalling and the complement system. The Y-axis represents the top functions as calculated by IPA based on differentially expressed genes are highlighted and the $X$-axis represents the ratio of the number of genes from the dataset that map to the pathway and the number of all known genes ascribed to the pathway. The orange threshold line marks the $p=0.05$. The threshold of $p$-value $<0.05$ as calculated by Fischer's test. C IPA identified most highly rated network. The network representation of the most highly rated network. Complement C3, Complement C4a/C4b, Alpha-2-macroglobulin (A2M), Serpin family F member 1 (SERPINF1) that are shaded were determined to be significant from the statistical analysis. These proteins shaded dark blue are upregulated and those that are light blue are downregulated. A solid line represents a direct interaction between the two proteins
} 


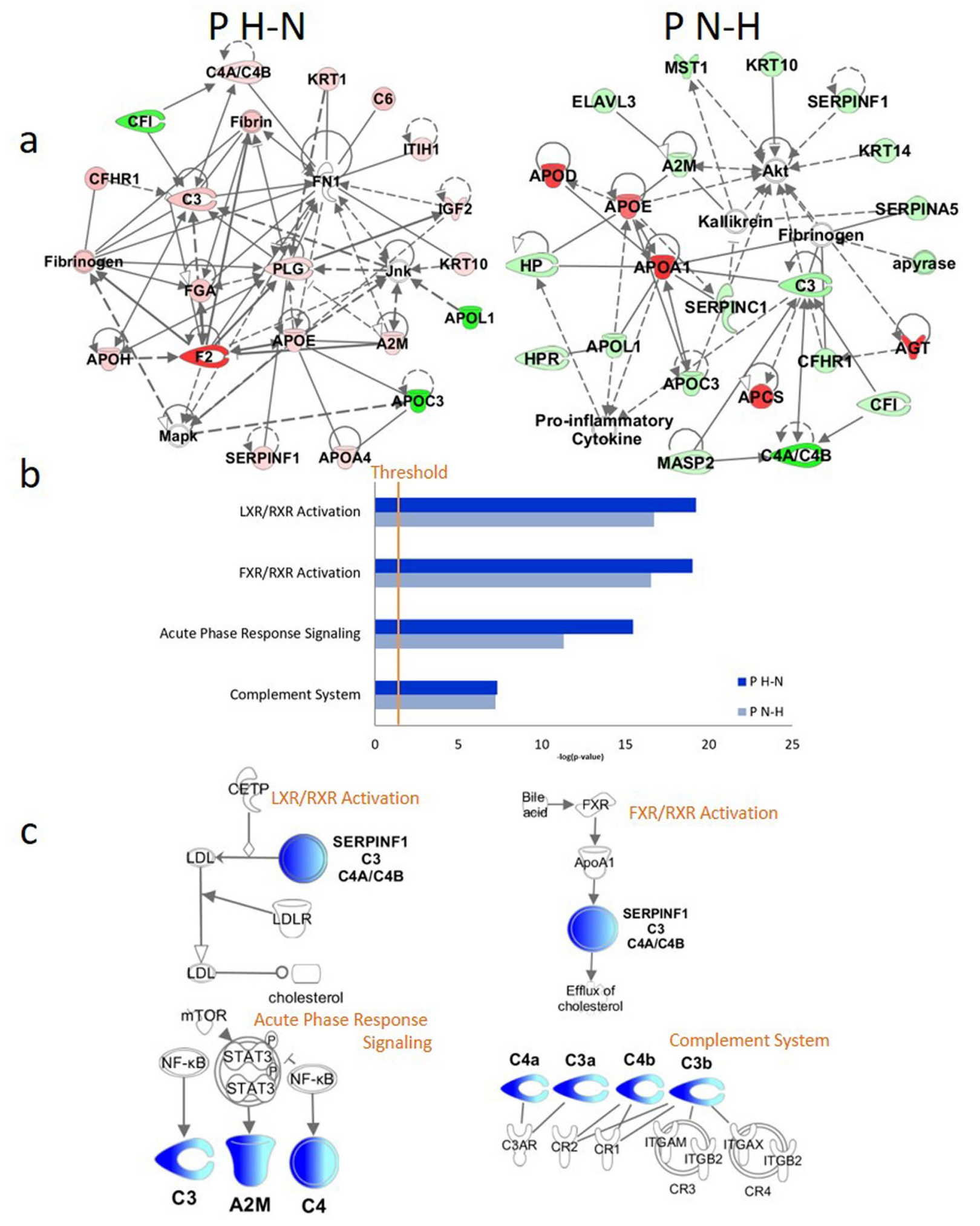

Fig. 2 (See legend on previous page.) 


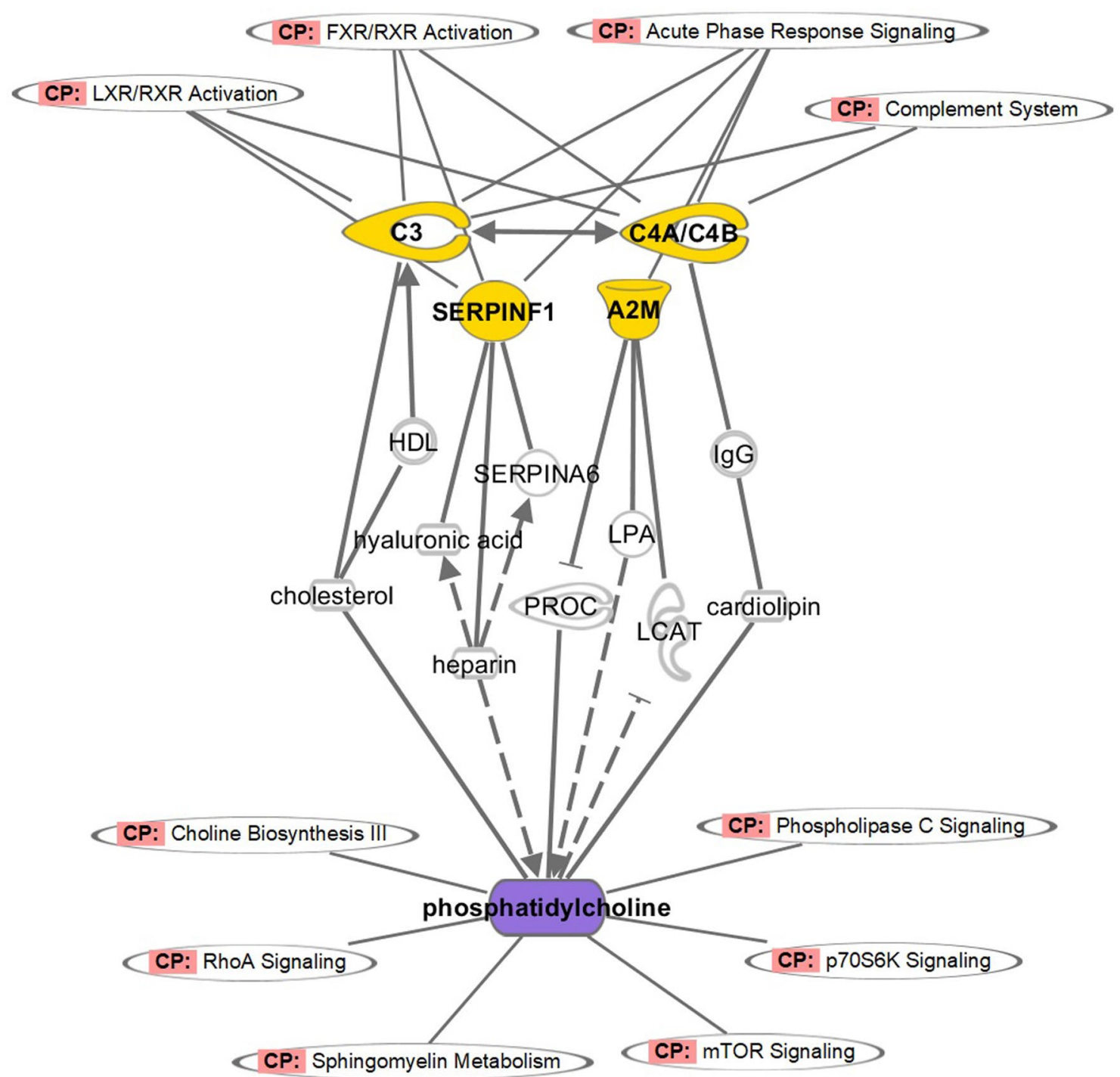

Fig. 3 Network analysis identifies metabolites and protein clusters of functional importance in Hypertensive Patients with Phlegm-Dampness Syndrome. The reconstructed network contains, Complement C3, Complement C4a/C4b, A2M, SERPINF1 (yellow) and PC (purple). Edges (lines and arrows between nodes) represent direct (solid lines) and indirect (dashed lines) interactions between molecules as supported by information in the Ingenuity knowledge base. Node shapes represent functional classes of gene products, rectangles with solid lines for cytokines, rectangles with dotted lines for growth factors, triangles for phosphatases, concentric circles for groups or complexes, diamonds for enzymes, and ovals for transcriptional regulators or modulators

those, Complement C3, Complement C4a/C4b, A2M, SERPINF1 have essentially the same tendencies of variation in both $\mathrm{H}-\mathrm{N}$ and $\mathrm{N}-\mathrm{H}$ group (Fig. 2A). Evidence suggests that $\mathrm{C} 3$ and $\mathrm{C} 4$ are both increased in chronic inflammation [44, 45]. A recent large cohort study with 2000 healthy men with an average of 15 years follow-up reported the association of the complement system with HTN pathogenesis [45]. This study has shown that the subjects with a high baseline C3 levels were at a higher risk of developing HTN in later life irrespective of any sort of interference of risk factors. Even at the baseline, the levels of $\mathrm{C} 3$ and $\mathrm{C} 4$ were found to be well correlated with the blood pressure of the subjects [45]. Within the similar pace, our results also indicated the higher relevance of $\mathrm{C} 3(\mathrm{~N}-\mathrm{H}:-2.7 ; \mathrm{H}-\mathrm{N}:+2.5), \mathrm{C} 4 \mathrm{a}(\mathrm{N}-\mathrm{H}:-6.5$; $\mathrm{H}-\mathrm{N}:+1.5)$ in the considered obese HTN subjects. The C3 and C4a levels were found to be elevated in our study subjects as well (Fig. 2B, C). Certainly, this indication is quite consistent with the existing established knowledge from the large study [45]. C3 is also being considered as 
an essential factor in the pathogenesis of HTN due to its maintenance effect on undifferentiated mesenchymal cells. There was enough evidence suggesting the connection between inflammation and HTN, but the specific mechanisms of complement systems were not well explored in HTN pathogenesis [46]. It is indeed a deep area for further investigation to reveal the mechanistic insights and the comprehensive interactions between HTN and inflammation. On the other hand, retinoid X receptor (RXR), that plays an important role in cardiac development and whose impairment is linked to developing cardiovascular diseases [47]. They serve as the major target for a group of transcription factors, Liver $\mathrm{X}$ receptor (LXR) $\alpha$ and $\beta$ belonging to the nuclear receptor (NR) superfamily [47]. They form heterodimers and bind to the RXR. RXR agonists were found to inhibit HTNinduced myocardial hypertrophy by modulating p70S6K signalling pathway [48]. Possible involvement of dysregulated LXR signalling in human obesity has been proposed in several independent studies $[49,50]$. Although data from murine models discussed above suggest that LXR have several beneficial effects, including reduced cardiovascular risk related enhanced reverse cholesterol transport, increased glucose uptake, the attenuated release of pro-inflammatory factors, increased lipid oxidation and reduced atherosclerosis, data on the systemic effects of LXR agonists in humans are lacking. The farnesoid X receptor (FXR) is a type of nuclear receptor that functions as an endogenous sensor for bile acids (BAs). Our data has also predicted the activation of FXR/RXR pathway. Upon activation, FXR heterodimerizes with RXR and regulates genes involved in the cholesterol synthesis pathway (Fig. 2C). Cholesterol is one of the strongest inverse predictors for cardiovascular diseases. Data from our study also offered a set of proteins and interactors such as HDL, Cardiolipin, LPA (Fig. 3) those are linked to cardiovascular physiology and their impairments may lead to cardiovascular diseases. Considering the functional evidence endorsing our results, a systematic study identified A2M-related biological processes getting perturbed in the pathophysiology of Alzheimer's diseases. Besides, the gene, SERPINF1 was found to encode a pigment epithelium-derived factor, a multi-functional protein that exhibits neurotrophic and anti-angiogenic activity [51]. These findings together must lead to powerful support in the view of epidemiological studies in which the changes in body weight has been demonstrated as a risk factor for developing HTN.

The best strength of our study is that the data are longitudinal, and our mode of analysis integrated two cuttingedge methods, metabolomics, and proteomics. It has several prominent advantages in translational clinical science. However, encompassing the maximum number of variables, such as ethnicity, race etc. and their effects on the study subjects were kept out of consideration in this study designs. This is a limitation in this study as well as a small number of participants. They may have a potential impact on the proteome or metabolome levels which were not explored. All study subjects were Han Chinese in our study, and we have strictly defined the criteria to reduce the potential sample bias. Moreover, having a larger dataset, especially more samples of HTN with PDS compare to non PDS, and is warranted to support these preliminary findings. It was also shown that greasy food, lack of exercise, and smoking were all important factors of the PDS, dynamic monitoring these factors is needed in further studies.

\section{Conclusions}

In conclusion, the combined serum proteomic and metabolomic profiling reveals a link between the complement system, altered phosphatidylcholine metabolism and HTN patients with body weight changes. PC, Complement C3, Complement C4a/C4b, A2M and SERPINF1 were identified as the strongest predictors of HTN patients' weight changes. The present study also clarified critical pathways that function in HTN patients with body weight changes, they are important resource to support HTN biomarker discovery. Future studies with larger cohorts are required to validate these findings.

\section{Abbreviations \\ A2M: Alpha-2-macroglobulin; BP: Blood pressure; BMI: Body mass index; DBP: Diastolic blood pressure; FXR: Farnesoid X receptor; HTN: Hypertension; IPA: Ingenuity pathway analysis; Kg: Kilogram; LC-Q-TOF-MS: Liquid chromatogra- phy quadrupole-time-of-flight mass spectrometer; LXR: Liver X receptor; NR: Nuclear receptor; PC: Phosphatidylcholine; PDS: Phlegm-Dampness Syndrome; RhoA: Ras homolog gene family member A; RV: Representative value; RXR: Retinoid X receptor; SERPINF1: Serpin family F member 1.}

\section{Authors' contributions}

Conceptualization-AL and CZ, methodology-CZ, SC LL and TY, software-XL, validation-SC, TY and NZ, formal analysis- $X \mathrm{~L}$, resources- $\mathrm{XL}$, data curation- $\mathrm{CL}$, original draft preparation- $C Z$, review and editing- $A L$ and $D C$, visualization- $L L$ and $\mathrm{DC}$, supervision- $\mathrm{XH}$ and $\mathrm{JM}$, project administration-CL, funding acquisition-AL. All authors have read and approved the final manuscript.

\section{Funding}

The study was supported by the National Natural Science Foundation of China (No. 81503449). The Dongzhimen Hospital Project [2020TSRC-002].

\section{Availability of data and materials}

The datasets generated and/or analyzed during the current study are available from the corresponding author upon reasonable request.

\section{Declarations}

\section{Ethics approval and consent to participate}

The informed consent for inclusion was taken consciously from all the participants included in this study. The study was conducted under the Declaration of Helsinki, and the protocol was approved by the Ethics Committee of the Institute of Basic Research in Clinical Medicine (No.201209). 


\section{Consent for publication \\ Not applicable.}

\section{Competing interests}

These authors declare that there are no conflicts of interest regarding this work.

\section{Author details}

${ }^{1}$ Dongzhimen Hospital, Beijing University of Chinese Medicine, Dongcheng District, Beijing 100700, China. ${ }^{2}$ Institute for Brain Disorders, Beijing University of Chinese Medicine, Beijing, China. ${ }^{3}$ Institute of Basic Research in Clinical Medicine, China Academy of Chinese Medical Sciences, Beijing, China. ${ }^{4}$ School of Nursing, Jiangxi University of Traditional Chinese Medicine, Nanchang, China. ${ }^{5}$ Institute of Integrated Bioinformedicine \& Translational Science, Hong Kong Baptist University, Kowloon Tong, Hong Kong, China. ${ }^{6}$ School of Pharmacy, Second Military Medical University, Shanghai, China. ${ }^{7}$ School of Chinese Medicine, Hong Kong Baptist University, Kowloon Tong, Hong Kong, China.

Received: 1 May 2021 Accepted: 26 June 2021

Published online: 07 July 2021

\section{References}

1. Kjeldsen S, Feldman RD, Lisheng L, Mourad JJ, Chiang CE, Zhang W, Wu Z, Li W, Williams B. Updated national and international hypertension guidelines: a review of current recommendations. Drugs. 2014;74(17):2033-51.

2. Whelton PK, Carey RM, Aronow WS, Casey DE, Wright JT. 2017 ACC/AHA AAPA/ABC/ACPM/AGS/APhA/ASH/ASPC/NMA/PCNA Guideline for the prevention, detection, evaluation, and management of high blood pressure in adults. A report of the american college of cardiology/american heart association task force on clinical practice guidelines. Hypertension. 2017;19(19):213-21

3. Mills KT, Bundy JD, Kelly TN, Reed JE, Kearney PM, Reynolds K, Chen J, He J. Global burden of hypertension: analysis of population-based studies from 89 Countries. J Hypertens. 2015. https://doi.org/10.1097/01.hjh. $0000469726.59998 . c c$

4. Rosendorff C, Lackland DT, Allison M, Aronow WS, Black HR, Blumenthal RS, Cannon CP, de Lemos JA, Elliott WJ, Findeiss L, et al. Treatment of hypertension in patients with coronary artery disease: a scientific statement from the American Heart Association, American College of Cardiology, and American Society of Hypertension. Hypertension. 2015;65(6):1372-407.

5. Mandal A. Study of prevalence of type 2 diabetes mellitus and hypertension in overweight and obese people. J Fam Med Prim Care. 2014;3(1):25.

6. Moore LL, Visioni AJ, Qureshi MM. Weight loss in overweight adults and the long-term risk of hypertension: the Framingham Study. ACC Curr J Rev. 2005:14(9):6-7.

7. Lu Y, Hajifathalian K, Ezzati M, Woodward M, Rimm EB, Danaei G. Metabolic mediators of the effects of body-mass index, overweight, and obesity on coronary heart disease and stroke: a pooled analysis of 97 prospective cohorts with 1.8 million participants. Lancet. 2014;383(9921):970-83.

8. Bogers RP, Bemelmans WJ, Hoogenveen RT, Boshuizen HC, Woodward M, Knekt P, van Dam RM, Hu FB, Visscher TL, Menotti A, et al. Association of overweight with increased risk of coronary heart disease partly independent of blood pressure and cholesterol levels: a meta-analysis of 21 cohort studies including more than 3,00,000 persons. Arch Intern Med. 2007;167(16):1720-8.

9. Ferland A, Eckel RH. Does sustained weight loss reverse the metabolic syndrome? Curr Hypertens Rep. 2011;13(6):456-64.

10. Somes GW, Kritchevsky SB, Shorr RI, Marco P, Applegate WB. Body mass index, weight change, and death in older adults: the systolic hypertension in the elderly program. Am J Epidemiol. 2002;2:132.

11. Yang G, Shu XO, Gao YT, Zhang X, Li H, Zheng W. Impacts of weight change on prehypertension in middle-aged and elderly women. Int J Obes. 2007;31(12):1818.

12. Cordero A, Bertomeu-Martínez V, Mazón P, Martín-Raymondi D, Palma JL, Anguita M, Lekuona IA, Galve E, González-Juanatey JR. Short-term metabolic changes achieved by weight loss in hypertensive patients. Int J Cardiol. 2011;153(3):286-90.
13. Jiang M, Lu C, Zhang C, Yang J, Tan Y, Lu A, Chan K. Syndrome differentiation in modern research of traditional Chinese medicine. J Ethnopharmacol. 2012;140(3):634.

14. Wang J, Wang Q, Li L, Li Y, Zhang H, Zheng L, Yang L, Zheng Y, Yang Y, Peng G. Phlegm-dampness constitution: genomics, susceptibility, adjustment and treatment with traditional Chinese medicine. Am J Chin Med. 2013;41(2):253-62.

15. Wu QF, Wen MX, Lan DH. Effects of Banxia Baizhu Tianma Decoction on Insulin Resistance and Blood Lipid of Hypertension with Abundant Phlegm-dampness Syndrome. J Fujian Coll Tradit Chin Med. 2007; 17(2):8-10.

16. Wang Q, Gong H, Gao J. Study on Characteristics of Peripheral Blood Gene Expression Profile in the Obesity with Phlegm-Dampness Constitution. J Tradit Chin Med. 2006:47:851-8.

17. World Health Organization. Regional Office for the Western Pacific. (2007)! WHO international standard terminologies on traditional medicine in the Western Pacific Region. Manila : WHO Regional Office for the Western Pacific. https://apps.who.int/iris/handle/10665/206952

18. Chu YG, Shi J, Hu YH, Wu HQ, Liu GJ, Hu CJ, Li YZ, Li Y, Chen ZJ, He Q. Serum proteomes of hypertension patients with abundant phlegmdampness. J Integr Med. 2009;7(7):629-35.

19. Guo X, Zhang G. Health intervention for hypertension patients with phlegm-dampness syndrome. World J Integr Tradit West Med. 2016;11(4):537-9.

20. Flaws B, Sionneau P. The treatment of modern western diseases with Chinese medicine. Torrance: Blue Poppy Press; 2004.

21. Delles C, Neisius U, Carty DM. Proteomics in hypertension and other cardiovascular diseases. Ann Med. 2012;44(Suppl 1):S55-64.

22. Fuchs FD, de Mello RB, Fuchs SC. Preventing the progression of prehypertension to hypertension :role of antihypertensives. Curr Hypertens Rep. 2014. https://doi.org/10.1007/s11906-014-0505-1.

23. Levy D, Larson MG. The progression from hypertension to congestive heart failure. JAMA. 1996. https://doi.org/10.1001/jama.1996.0353044003 7034.

24. De Marco M, De Simone G, Roman MJ, Chinali M, Lee ET, Russell M, Howard BV, Devereux RB. Cardiovascular and metabolic predictors of progression of prehypertension into hypertension: the Strong Heart Study. Hypertension. 2009;54(5):974.

25. Stewart PA, Li J, Fisher KJ, Dhungana S, Stewart D, Sumner S, Gardner E, Poirier J, Rudin CM, Welsh EA. Abstract 3752: Integrating proteomics and metabolomics characterizes active pathways and potential drug targets in small cell lung cancer. Can Res. 2015;75(15 Supplement):3752.

26. Cai Z, Zhao JS, Li JJ, Peng DN, Wang XY, Chen TL, Qiu YP, Chen PP, Li WJ, Xu LY. A combined proteomics and metabolomics profiling of gastric cardia cancer reveals characteristic dysregulations in glucose metabolism. Mol Cell Proteomics. 2010;9(12):2617.

27. China Association of Chinese Medicine. Classification and determination of Constitution in TCM. China Traditional Chinese Medicine Publishing House Beijing, 2009.

28. Garvey WT, Garber AJ, Mechanick JI, Bray GA, Dagogo-Jack S. American association of clinical endocrinologists and american college of endocrinology position statement on the 2014 advanced framework for a new diagnosis of obesity as a chronic disease. Endocr Pract. 2014. https://doi. org/10.4158/EP14280.PS.

29. James PA, Oparil S, Carter BL. evidence-based guideline for the management of high blood pressure in adults: report from the panel members appointed to the eighth joint national committee (JNC 8). JAMA. 2014. https://doi.org/10.1001/jama.2013.284427.

30. Mancia G, Fagard R, Narkiewicz K, Redon J, Zanchetti A, Bohm M, Redón J, Böhm M, Christiaens T, Cifkova R. 2013 ESH/ESC practice guidelines for the management of arterial hypertension: the task force for the management of arterial hypertension of the European Society of Hypertension (ESH) and of the European Society of Cardiology (ESC). Blood Press. 2013;16(3):135

31. Yong T, Xinru L, Ke Z, Xiaojuan H, Cheng L, Bing H, Xuyan N, Cheng X, Gang $X$, Zhaoxiang B. The potential biomarkers to identify the development of steatosis in hyperuricemia. PLoS ONE. 2016;11(2):e0149043.

32. Berdel WE, Hoff DDV, Unger C, Schick HD, Fink U, Reichert A, Rastetter EJ. Ether lipid derivatives: antineoplastic activity in vitro and the structureactivity relationship. Lipids. 1986. https://doi.org/10.1007/BF02536417. 
33. Sekas G, Patton GM, Lincoln EC, Robins SJ. Origin of plasma lysophosphatidylcholine: evidence for direct hepatic secretion in the rat. J Lab Clin Med. 1985;105(2):190-4.

34. Chapman MJ, Sposito AC. Hypertension and dyslipidaemia in obesity and insulin resistance: pathophysiology, impact on atherosclerotic disease and pharmacotherapy. Pharmacol Ther. 2008;117(3):354-73.

35. Floegel A, Drogan D, Weikert C, Pischon T, Dietrich S. Identification of serum metabolites associated with incident hypertension in the European Prospective Investigation into Cancer and Nutrition-Potsdam Study. Hypertension. 2016. https://doi.org/10.1161/HYPERTENSIONAHA.116. 07292.

36. Kulkarni H, Meikle PJ, Mamtani M, Weir JM. Plasma lipidomic profile signature of hypertension in Mexican American families: specific role of diacylglycerols. Hypertension. 2013. https://doi.org/10.1161/HYPERTENSI ONAHA.113.01396.

37. Li L, Yang J, Lu CF. A study on the correlation of erythrocyte membrane phospholipids with lipid peroxidation and blood rheology in patients with essential hypertension. Chin J Cardiol. 1995; 23(003):188-190.

38. Bienias K, Fiedorowicz A, Sadowska A, Prokopiuk S, Car H. Regulation of sphingomyelin metabolism. Pharmacol Rep. 2016:68:570-81.

39. Medeiros C, Frederico MJ, Luz GD, Pauli JR, Silva ASR, Pinho RA, Velloso LA, Ropelle ER, Souza CTD. Exercise training reduces insulin resistance and upregulates the mTOR/p70S6k pathway in cardiac muscle of dietinduced obesity rats. J Cell Physiol. 2011;226(3):666-74.

40. Anaruma CP, Pereira RM, Rodrigues KCDC, Silva ASRD, Moura LPD. Rock protein as cardiac hypertrophy modulator in obesity and physical exercise. Life Sci. 2019:254:116955.

41. Jin L. Increased RhoA/Rho-kinase signaling mediates spontaneous tone in aorta from angiotensin II-induced hypertensive rats. J Pharmacol Exp Ther. 2006;318(1):288-95.

42. Nunes KP, Rigsby CS, Webb RC. RhoA/Rho-kinase and vascular diseases: what is the link? Cell Mol Life Sci. 2010;67(22):3823.

43. Qian YS, Zhang Y, Zhou XO. Correlation study on serum adiponectiin abnormity with adiponectin gene polymorphisms in hypertensive patients of phlegm-dampness constitution. Chin J Integr Med. 2010;30(5):4.

44. Copenhaver M, Yu CY, Hoffman R. Complement components, C3 and C4, and the metabolic syndrome. Curr Diabetes Rev. 2018;15(1):44-8.
45. Engström G, Hedblad B, Berglund G, Janzon L, Lindgärde F. Plasma levels of complement C3 is associated with development of hypertension: a longitudinal cohort study. J Hum Hypertens. 2007;21(4):276-82.

46. Nadar SK, Lip GYH. New insights into complement C3 and inflammation in hypertension. J Hum Hypertens. 2007;21(4):261-3.

47. Pérez E, Bourguet W, Gronemeyer H, Lera ARD. Modulation of RXR function through ligand design. Biochim Biophys Acta. 2012;1821(1):57-69.

48. Zhu J, Ning RB, Lin XY, Chai DJ, Xu CS, Xie H, Zeng JZ, Lin JX. Retinoid X receptor agonists inhibit hypertension-induced myocardial hypertrophy by modulating LKB1/AMPK/p70S6K signaling pathway. Am J Hypertens. 2014. https://doi.org/10.1093/ajh/hpu017.

49. Dahlman I, Nilsson M, Jiao H, Hoffstedt J, Lindgren CM, Humphreys K, Kere J, Gustafsson JK, Arner P, Dahlman-Wright K. Liver X receptor gene polymorphisms and adipose tissue expression levels in obesity. Pharmacogenet Genomics. 2006;16(12):881-9.

50. Schultz JR, Tu H, Luk A, et al. Role of LXRs in control of lipogenesis. Genes \& Development. 2000;14(22):2831-2838.

51. Ren JG, Jie C, Talbot C. How PEDF prevents angiogenesis: a hypothesized pathway. Med Hypotheses. 2005;64(1):74-8.

\section{Publisher's Note}

Springer Nature remains neutral with regard to jurisdictional claims in published maps and institutional affiliations.
Ready to submit your research? Choose BMC and benefit from:

- fast, convenient online submission

- thorough peer review by experienced researchers in your field

- rapid publication on acceptance

- support for research data, including large and complex data types

- gold Open Access which fosters wider collaboration and increased citations

- maximum visibility for your research: over $100 \mathrm{M}$ website views per year

At BMC, research is always in progress.

Learn more biomedcentral.com/submissions 